\title{
A PIAUIENSIDADE COMO IDENTIDADE CULTURAL NA FORMAÇÃO DE PEDAGOGOS: RELATO DE EXPERIÊNCIA DO PROJETO DE VISITA AO MUSEU DO PIAUÍ
}

\section{PIAUIENSIDADE (PIAUI's CULTURAL TRAITS) AS A CULTURAL IDENTITY IN THE EDUCATION OF EDUCATION PROFESSIONALS: EXPERIENCE REPORT OF THE VISIT PROJECT TO THE PIAUÍ MUSEUM}

\author{
Douglas Pereira da Costa* \\ ORCID: https://orcid.org/0000-0003-0706-7163 \\ Antonieldo Araújo de Freitas** \\ ORCID: https://orcid.org/0000-0001-7512-1956
}

\section{RESUMO:}

O estudo é um relato de experiência do Projeto "Arte, Cultura e História Piauienses: Visita ao Museu do Piauí", em Teresina (PI), desenvolvido com graduandos de Pedagogia de uma faculdade privada do Piauí. O projeto descrito no texto objetivou propiciar reflexões entre os alunos e despertar o senso de responsabilidade pela preservação, promoção e transmissão dos traços culturais piauienses. Retrata o sentido visto e ouvido pelo professor durante a visita ao museu, bem como os sentidos e significados construídos pelos alunos, que foram compartilhados em uma roda de conversas entre alunos e professor. Os resultados validam a piauiensidade como identidade cultural e evidenciam que, quando se vive e se sente pertencente a uma identidade cultural relacionada com seu campo de atuação, por ações conscientes e reflexivas, o pedagogo torna-se responsável e agente de preservação, promoção e transmissão desses traços culturais para gerações atuais e futuras nos contextos escolares.

Palavras-chave: Piauiensidade; Identidade cultural; Museu do Piauí; Pedagogo; Formação de professores.

\begin{abstract}
:
The article is an experience report of the Project "Arte, Cultura e História Piauienses: Visita ao Museu do Piauí" (Piaui's Art, Culture and History: Visit to the Piauí Museum), in Teresina (PI), developed with undergraduate students in the Education Course from a private college in Piauí. The project described in the text aimed to provide reflection among students and awaken a sense of responsibility for the preservation, promotion and transmission of Piauí's cultural traits. It portrays the sense, seen and heard by the teacher during the visit to the museum, as well as the senses and meanings constructed by the students, which were shared in a circle of conversations between students and teacher. The results validate the piauiensidade as a cultural identity and show that, when educators live and feel belonging to a cultural identity related to their field of action, through conscious and reflective actions, they becomes responsible for it and agents of preservation, promotion and transmission of these cultural traits for current and future generations in school contexts.
\end{abstract}

Keywords: Piauiensidade; Cultural identity; Museu do Piauí. Educator; Teacher education. 


\section{Introdução}

O Piauí possui suas raízes culturais vinculadas às diversas áreas da vida do seu povo, porém, para muitos teóricos, vivemos dias de crises nas identidades culturais derivadas dos muitos fatores do mundo contemporâneo que ocasionam mudanças rápidas e repentinas no modo de viver das pessoas, que para Hall (2004), fragmentam as paisagens culturais nos mais variados aspectos de marcadores identitários, a exemplo do gênero, da sexualidade, da etnia e da nacionalidade, que anteriormente forneciam sólidas localizações aos indivíduos sociais.

Dessa forma, tais marcas correm o risco de ficarem perdidas ao longo do tempo e, como consequência, a piauiensidade, de ser usurpada. Dias (1999 apud SOUZA, 2008, p. 9), afirma que "existe uma visão sedimentada na mentalidade nacional de considerar o Piauí como uma unidade da federação brasileira sem expressividade, sem identidade e até mesmo sem história". Em uma expressão mais forte, a autora afirma que "o próprio piauiense praticamente desconhece sua história".

Diante desse cenário, a educação possui o papel de instigar o resgate dos valores culturais por meio de ações que proporcionem aos alunos o conhecimento e a valorização da história e das manifestações culturais do Piauí. Sendo assim, este relato é resultante das reflexões posteriores à efetivação do Projeto "Arte, Cultura e História Piauienses: Visita ao Museu do Piauî", desenvolvido com graduandos de Pedagogia de uma faculdade privada do Piauí durante as aulas do componente curricular "Conteúdos e Didática da Arte", o projeto objetivou propiciar reflexões entre os futuros profissionais da educação e despertar o senso de responsabilidade pela preservação, promoção e transmissão dos traços culturais piauienses para gerações atuais e futuras.

Os Parâmetros Curriculares Nacionais de Arte (BRASIL, 1997), documentos mais que históricos, mas de contextos orientadores da educação básica, definem o professor como um criador de situações de aprendizagem e traz o trabalho por projetos como orientação didática no ensino da Arte, desenvolvidos em caráter interdisciplinar ou dentro de uma linguagem artística específica. Esse aporte teórico reveste o profissional pedagógico da missão e do poder de propagar os conhecimentos de níveis culturais e, assim, "o professor deve estar consciente de que o estudo da cultura popular constitui um instrumento eficaz para a compreensão do homem e da comunidade" (OLIVEIRA, 1975, p. 47).

Nessas circunstâncias, o relato de experiência pretende problematizar a importância do sentimento de pertencimento a uma identidade cultural na formação de professores, mais especificamente na constituição formativa de pedagogos, trazendo uma reflexão sobre o resgate, o conhecimento e a preservação da cultura nos termos da piauiensidade. Para isso, inicialmente, apresenta uma abordagem teórica que elucida a piauiensidade como identidade cultural; posteriormente, o projeto é descrito e fundamentado metodologicamente, para então relatar sobre o sentido visto e ouvido durante e após a visita ao Museu do Piauí, em Teresina, Estado do Piauí. E, por fim, transcreve as considerações finais. 


\section{A Piauiensidade como identidade cultural}

Em um país com a dimensão do Brasil e com a vasta pluralidade de culturas, identificamos traços e características que identificam povos de um determinado local, estado ou mesmo região nacional. Nessa perspectiva, piauiensidade é uma expressão que ganha força quando tratamos das memórias, histórias e fundamentos culturais do povo piauiense. Souza (2008, p. 7) define essa piauiensidade como o "termo que sintetiza os atributos que identificam o Estado do Piauí, o que ele é ou o que o diferencia no conjunto das alteridades federativas".

Para Moraes (2012), a piauiensidade é mais que o conceito de um termo, é um estado de espírito, do qual motiva a valorá-la com formas inovadoras para acompanhar as transformações globais, definindo-a como uma identidade cultural de peculiaridades do Piauí nas mais diversas dimensões, nos princípios pré-históricos, na concepção de cultura popular em seus contextos folclóricos, nas narrativas históricas em todos os períodos, nos feitos marcantes dos heróis piauienses, na religiosidade e crenças esculpidas por essa população, é aquilo que originou das entranhas do povo de solo piauiense.

Conforme o dito popular piauiense, de que "no Piauí, existe um sol para cada pessoa", pode-se arriscar em dizer que até a dimensão do calor solar é uma particularidade do território desse Estado, caso comparado ao dos demais. Ao escrever a letra do hino estadual, Da Costa e Silva (1823) enfatiza: "Piauí, terra querida, filha do sol do Equador", ou seja, há quase 200 anos, o poeta já declarava essa possível singularidade do território dessa unidade da Federação.

Conforme Hall (2004), a identidade cultural compreende aspectos que emergem da noção de pertencimento a culturas, que se adentram nas dimensões étnicas, de raças, religiosas e em amparo à concepção dos aspectos nacionais. Assim, entende-se que a identidade é assimilada através do pertencimento a ela. Porém, o autor chama atenção ao afirmar que esse pertencimento pode ser desalojado pela globalização, como vemos a seguir:

Quanto mais a vida social se torna mediada pelo mercado global de estilos, lugares e imagens, pelas viagens internacionais, pelas imagens da mídia e pelos sistemas de comunicação globalmente interligados, mais as identidades se tornam desvinculadas desalojadas - de tempos, lugares, histórias e tradições específicos. (HALL, 2004, p. 75).

A compreensão da identidade de um local é fundamentada pela procura de entrelaçar falas, discursos e as concepções que são estabelecidas sobre o mesmo, assim, "o Piauí de hoje é, repetimos, a resultante dos diversos componentes de sua formação histórica, étnica, social e econômica" (OLIVEIRA, 1977, p. 7-8). Nessas significações, a piauiensidade como identidade é interpretada como resultado daquilo que muitos falaram e estabeleceram como conceito, e mais precisamente, é fruto do emaranhado de fatores citados pelo autor que foram determinantes na formação dessa identidade. 
Porém, Borges (2012) relata que os maiores veículos de mídia nacional, por alguns momentos, divulgam o Piauí como a ovelha negra da nação, como povo e Estado que não evoluem. Esse fato pode ocasionar uma imagem negativa, assim, a piauiensidade é "o resultado deste acúmulo de camadas discursivas que há bastante tempo vem lançando, sobre o Estado e o povo, imagens que se cristalizaram e que juntas inventam o Piauí e o piauiense" (BORGES, 2012, p. 2). De certo, os discursos sobre um povo são responsáveis por construir sua identidade para que outros assim a percebam. Dessa forma, compreende-se a necessidade de veicular discursos promovedores da piauiensidade como aspecto de extremo valor e positividade, inclusive, em contribuições essenciais para o desenvolvimento brasileiro nas mais diversas áreas.

No entanto, a piauiensidade ainda pode ser descrita como algo bem mais subjetivo que envolve sentimentos e percepções sobre ângulos diversos. Moraes (2012) vincula o ser piauiense ao sentimento de amor pelos símbolos estaduais, às raízes da história, à reverência à cultura folclórica do bumba-meu-boi e danças de reisados, bem como ao respeito pelas diversidades, sejam de raças ou crenças religiosas, ou mesmo, pelos vaqueiros, considerados símbolos da cultura do Piauí. Nesse entremeio, ainda o relaciona às características pessoais do povo comunitário, intrépido, de fé e cheio de esperanças e perspectivas por um bom futuro. Ainda, historicamente, faz menção ao contexto histórico dos primeiros povos das Américas, referindo-se ao Parque Nacional da Serra da Capivara, em São Raimundo Nonato. Também cita os carnaubais, buritis e babaçus, espécies de palmeiras essenciais na produção de vários produtos, sejam artefatos culturais ou resultados de processos industriais. Finalizando, enfatiza que ser piauiense é ter a alegria de ser do Piauí, povo que as dificuldades não amedrontam, fazendo alusão à legenda do brasão da Unidade da Federação.

\section{O Projeto e o seu viés metodológico}

Em concepções metodológicas, este estudo trata-se de um relato de experiência. Conforme Daltro e Faria (2019), o relato de experiência possui natureza qualitativa e enquadrase como uma espécie de narrativa científica e de multiplicidades teórico-metodológicas, que contempla o caráter descritivo, ou que mesmo chega a ultrapassá-lo. Nesse caso, a experiência é o objeto de análise do estudo, em que o processo interpretativo perpassa pelos olhares dos pesquisadores com sentidos polissêmicos e culturais.

Não obstante, a experiência é única e seus relatos partem de um lugar de fala pessoal, como referencia Larrosa (2016). Compreende-se que o professor é uma pessoa e uma parte importante desta é o professor (NÓVOA, 1992). Nesse aspecto, o adulto aprende com aquilo que está intimamente ligado à sua experiência, em um quadro conceitual de produção de saberes. 
Dessa forma, o estudo tem como objeto o Projeto "Arte, Cultura e História Piauienses: visita ao Museu do Piauí" e propõe-se a analisar as experiências vivenciadas pelos sujeitos participantes. E, ao tempo em que considera a cientificidade, também atenta para os aspectos subjetivos (DALTRO; FARIA, 2019) da formação identitária dos envolvidos. Nessas concepções, os resultados são apresentados com base nos discursos dos alunos e professor que protagonizaram a execução do projeto, os quais concordaram plenamente com a divulgação de seus pensamentos e imagens, atribuindo a conformidade ética necessária aos estudos com experimentação humana, confirmado pela assinatura em Termo de Consentimento Livre e Esclarecido (TCLE).

Para Oliskovicz e Dal Piva (2014), a prática docente baseada em projetos para estudantes de ensino superior como ações educativas necessitam de um propósito definido a ser alcançado por meio do esforço motivado, com aspectos básicos como: desenvolvimento do raciocínio para fins de aplicação na vida real; superação da mera memorização de informações; despertar do aluno para um pensamento com valorização funcional; situações reais que, integradas aos pensamentos, sentimentos e ações do estudante, gerem aprendizagens; tornar o aluno um pesquisador em busca de soluções para eventuais problemas; e, por fim, uma abordagem interdisciplinar como fator resulto da globalização do ensino.

Sob essa visão, compreende-se que o método se concentra no estudante ativo, tendo o professor como facilitador e orientador. A partir disso, por meio de projetos, desenvolvem-se estudos e aprendizagens significativos. Nessa perspectiva, o projeto relatado no presente estudo enquadra-se como de grande valia no processo formativo e de construção de saberes experienciais dos envolvidos. Por tal razão, pretende-se compartilhar a experiência através deste texto.

\section{O Projeto Arte, Cultura e História Piauienses: Visita ao Museu do Piauí}

O Projeto Pedagógico "Arte, Cultura e História Piauienses: Visita ao Museu do Piauí" integrou o plano de curso do componente curricular "Conteúdos e Didática da Arte", executado para uma turma de Pedagogia de uma faculdade privada. $\mathrm{O}$ projeto surge da inquietude e questionamentos do docente responsável pela disciplina, que se propôs a refletir sobre a necessidade de propiciar experiências significativas em torno da piauiensidade que se consubstanciam aos aportes teóricos discutidos e abordados em sala de aula.

Para isso, questionou-se o nível de conhecimento dos pedagogos em formação sobre as histórias, as culturas e as artes locais e regionais; indagou-se sobre quais impactos esse nível de conhecimento pode ocasionar no processo de ensino e aprendizagem de gerações futuras, ou mesmo atuais, no que tange à preservação da identidade cultural do estado piauiense; além disso, perguntou-se quais ações as escolas de educação básica e os cursos superiores de formação de professores têm desenvolvido para manterem vivas as memórias da piauiensidade. 
Como resposta do último questionamento, o professor refletiu sobre o que ele poderia fazer na situação em que ocupava e diante de um componente curricular convidativo a excelentes experiências. Assim, ciente da indissociabilidade entre ensino, pesquisa e extensão da educação superior (BRASIL, 1986), articulou desenvolver este projeto como prática pedagógica que transpôs os muros da universidade, que se estende de alguma forma até a comunidade, que instiga a curiosidade investigativa e de pesquisa do acadêmico e que, com tudo isso, constroem-se conhecimentos em um processo de ensino participativo.

Com base no artigo 43 da Lei de Diretrizes e Bases da Educação Nacional (LBD), Lei 9394/96, em especial o inciso III, que trata de uma das finalidades da educação superior: "incentivar o trabalho de pesquisa e investigação científica, visando o desenvolvimento da ciência e da tecnologia e da criação e difusão da cultura, e, desse modo, desenvolver o entendimento do homem e do meio em que vive" (BRASIL, 1996), o projeto propôs como objetivo proporcionar aos acadêmicos uma experiência de visita ao Museus do Piauí, em Teresina(PI). O intuito foi de propiciar reflexões entre os futuros profissionais da educação e despertar o senso de responsabilidade pela preservação, promoção e transmissão dos traços culturais piauienses para gerações atuais e futuras.

Dessa forma, o público-alvo restringiu-se a uma turma do curso de Licenciatura em Pedagogia, regime semipresencial, de uma faculdade privada com Polo de Educação na cidade de Aroazes (PI), composta por 17 alunos residentes no referido município (zona urbana e rural), localizado a $225 \mathrm{~km}$ da capital Teresina. No entanto, apenas 14 graduandos puderam participar da culminância do projeto na etapa de visita ao Museu do Piauí, porcentagem considerada significativa de sua totalidade.

Além do mais, o projeto teve como idealizador, elaborador, orientador e coordenador o professor do componente curricular. No entanto, não se descarta a percepção de que o projeto é um resultado conjunto de todos aqueles que, de alguma forma, se envolvem com ele. Como exemplo, pode-se mencionar que a comunidade local dos alunos foi essencial para a concretização do planejado, pois para realizar a viagem, os estudantes precisaram desenvolver atividades com fins de arrecadar fundos para custear as despesas e, nessa trajetória, encontraram todo o apoio da comunidade.

O desenvolvimento do projeto se deu em uma ordem de tempo cronológica no período de 4 de junho a 2 de julho de 2017, por tratar-se de uma turma em regime semipresencial, os componentes curriculares possuem curta duração. Dessa forma, todo o planejamento teve que ser executado em menos de um mês. Para tanto, quatro etapas foram estabelecidas.

\section{$1^{a}$ Etapa: Apresentação do Projeto}

A etapa consistiu na apresentação do projeto aos alunos, incluindo seus objetivos, intencionalidades e problematizações. Mais do que isso, foi o momento de 
averiguar se as questões-norteadoras especuladas pelo professor e que norteavam a construção do objetivo da proposta eram significativas e encontravam subsídio na realidade dos alunos. Isto posto, questionou-se os estudantes a respeito de tais problematizações. De fato, partindo do lugar de fala dos graduandos, as inquietações do docente faziam sentindo, inclusive ficou evidente que nenhum dos alunos teve a oportunidade de conhecer um ambiente com tanta marca e significância identitária como o Museu do Piauí.

$\mathrm{O}$ fato mencionado qualifica-se como justificativa para a execução do projeto.

\section{$2^{a}$ Etapa: Encontros para discussões e reflexões}

O segundo momento da execução do projeto diz respeito aos encontros proporcionados para reflexões e discussões em torno dos referenciais teóricos do componente curricular que seriam fundamentais para a concretização do projeto. Além do mais, esses momentos foram importantes para planejamento e decisões compartilhadas com os educandos sobre a etapa posterior e para programar as atividades que desenvolveram com fins de arrecadar fundos para custear as despesas da viagem, tais como transporte, entrada do museu e alimentação.

\section{$3^{a}$ Etapa: Visita ao Museu do Piauí}

No dia $1^{\circ}$ de julho de 2017, aconteceu a visita ao Museu do Piauí, em Teresina, capital do Piauí, de modo que alunos e professor realizaram uma viagem de Aroazes (PI) até Teresina (PI), num percurso de $225 \mathrm{~km}$, que ocorreu na madrugada do referido dia. Assim às $9 \mathrm{~h}$ adentrou-se ao museu.

\section{$4^{a}$ Etapa: Avaliações e relatos}

A última etapa promoveu a avaliação dos alunos pelo professor, em meio a uma roda de conversas e debates fundamentados pelas experiências expostas oralmente e capazes de demonstrar as percepções dos estudantes sobre os conhecimentos históricos, sociais, culturais e da arte piauiense e suas aplicações práticas na formação e prática docente, conforme as problematizações iniciais. Ressalta-se que a observação e o registro dos relatos serviram de subsídio para a análise e composição da discussão e resultados do estudo. Por fim, em conjunto, professor e alunos avaliaram o projeto.

\section{Da experiência em si: o sentido, visto e ouvido no Museu do Piaú}

A experiência de visita ao Museu do Piauí ocorreu no dia $1^{\circ}$ de julho de 2017 , depois de uma viagem de $225 \mathrm{~km}$ entre Aroazes e Teresina, quando professor e alunos 
chegaram à capital, conforme planejamento do projeto. O Museu do Piauí - Casa de Odilon Nunes, criado em 1941, fica localizado no Centro de Teresina, na Praça Marechal Deodoro da Fonseca. É um patrimônio cultural tombado pela Fundação Cultural do Piauí (FUNDAC) no ano de 1992.

\footnotetext{
O prédio, de linhas sóbrias, teve sua construção iniciada por volta de1859, pelo Comendador Jacob Manoel Almendra. De 1873 até 1925 o imóvel abrigou a sede do governo do Piauí. Entre 1926 a 1975 funcionou o Tribunal de Justiça. Em 1980, após a restauração passa a exercer a função de Museu do Piauí. Embora construído já no século XIX, o atual Museu do Piauí é um edifício de características neoclássicas, pela simetria da disposição das aberturas e modenatura bem marcada por pilastras. As aberturas são em arco plenas, emolduradas por cunhais em massa muito utilizada nas construções mais antigas de Teresina (PIAUÍ, 2009, não paginado).
}

Os participantes adentraram nos compartimentos da Casa de Odilon Nunes com a orientação de uma funcionária do museu, responsável por guiar, orientar, situar e explicar aos visitantes as salas e os compartimentos, suas representações e artefatos. Espera-se que esses relatos, fruto das observações do docente responsável pelo projeto, elucidados por pensamentos de teóricos ou veículos de notícias contemporâneos, sejam capazes de produzir nos leitores uma aproximação com tudo o que foi sentido, visto e ouvido naquele lugar.

Além de Museu do Piauí, ainda recebe a denominação de Casa de Odilon Nunes, em homenagem ao historiador que se dedicou a estudar e escrever sobre a história do Estado do Piauí. Esta foi a primeira informação transmitida pela guia e já provocou nos participantes um espanto, por nunca antes terem ouvido esse nome. Inicialmente, também foi dito que o Museu é composto por cerca de 7 mil peças catalogadas, que estão distribuídas em salas permanentes vinculadas ao processo histórico do Piauí.

Após sofrer uma reforma, o museu foi reaberto em março de 2017. Fábio Novo, como secretário de cultura do Piauí na época, afirmou que a reforma ocorreu de maneira ampla, indo além de aspectos físicos, com instalações novas. Um trabalho grandioso, realizado pelo arquiteto da UFPI, professor Paulo Vasconcelos, que se dedicou a percorrer o Piauí em suas extremidades para resgatar a memória dos piauienses, proporcionando maior contato com as culturas indígenas e afrodescendentes, enfatizando a importância desses povos para as origens e, consequentemente, para a história do Piauí (GOMES, 2017). 
Figura 1 - Alunos subindo as escadas de acesso às salas do Museu do Piauí

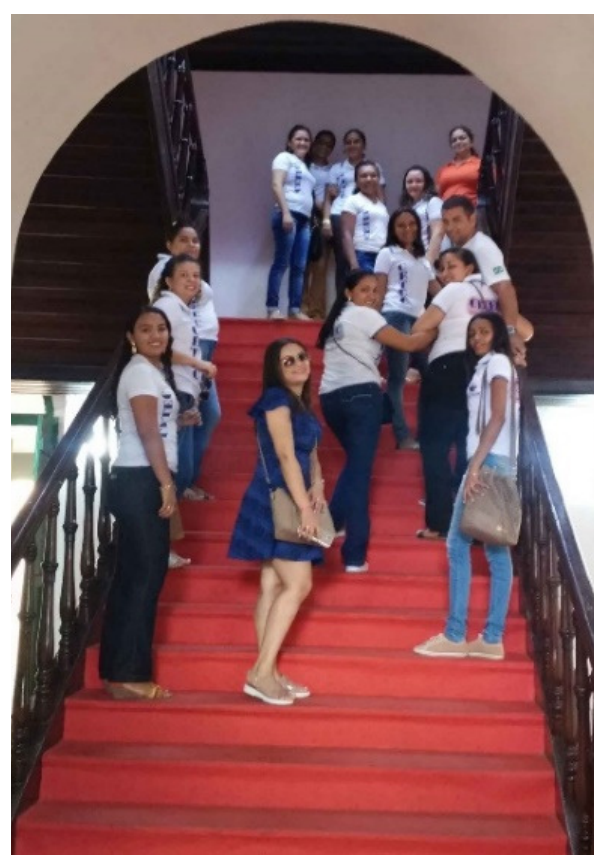

Fonte: Autores

Assim, chega o momento de subir as escadas do casarão, que conduzem os visitantes para os ambientes temáticos. O espaço da cultura indígena é o primeiro ambiente a ser visitado, expõe a memória de povos nativos das terras piauienses, em destaque aparecem imagens fotográficas de descendentes das comunidades indígenas remanescentes: Tabajaras de Nazaré, Ypi, Jaicós, Tucuns, Itacoatiara, Colheres de Pau e Cariri da Serra Grande, com desenhos em lajes de réplicas de pinturas rupestres de seus ancestrais. São exibidos machadinhas de pedras procedentes de Caracol (PI) e artefatos de decorações, caças e de outras finalidades, produzidos por esses povos. Em um olhar rápido e reflexivo, percebe-se o quanto esses artefatos exemplificam a influência indígena sobre os costumes local.

Organizada de maneira similar, a sala da cultura afro recepciona os visitantes com uma sonoplastia típica de suas tradições e estilos musicais. De certa maneira, os sons ecoados pela sala nos arremetem a imagens de momentos da escravidão, mesmo nunca tendo vivido em tal época. No entanto, ao percorrer o restante do que aquele ambiente tinha a oferecer, enxerga-se que o povo africano e seus descendentes possuem mais do que uma história de opressão, apesar de não ser possível negá-la, mas também possuem contribuições significativas para o processo de formação de uma identidade em nível estadual. Assim sendo, desbravam-se as raízes africanas em solo piauiense, deparando-se com a exemplificação das comunidades quilombolas: Olho d'água dos negros, Marinheiro, Mimbó, Potes, Salinas e Queimada Nova. 
Figura 2 - Representação das comunidades quilombolas

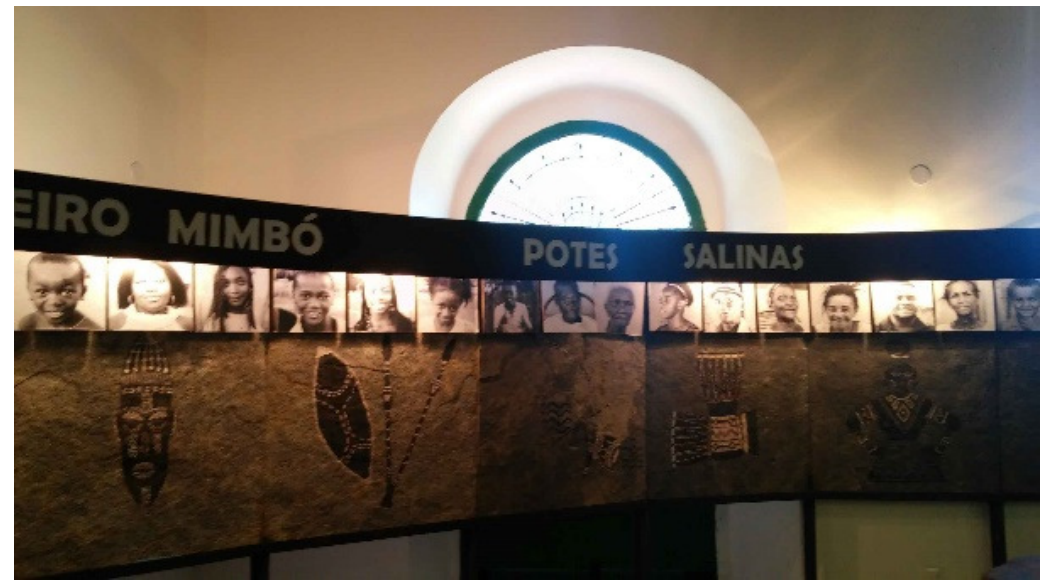

Fonte: Autores

Essa seção também contém objetos que enfatizam a tortura recebida pelos escravos na Fazenda Serra Negra, por volta dos meados do século XVIII, em que o proprietário Luís Carlos os maltratava com castigos severos. Localizada no limite entre Aroazes (PI) e Santa Cruz dos Milagres (PI), a fazenda se aproxima das histórias populares já conhecidas pelos alunos da turma, por se tratar de uma cultura local do município em que residem e por conhecerem o casarão histórico.

Além disso, conforme os relatos dos alunos, há a devoção por parte dos moradores da comunidade local da fazenda, também denominada de Serra Negra, a uma santa a que a esposa do Coronel Luís Carlos era devota. Assim, a "Fazenda não só testemunhou as lendas aterrorizantes que embalam a imaginação de sua população. Um profundo sentimento de fé é externado pelos habitantes que gravitam em seu território e à sua volta." (PIAUÍ, 2009, não paginado).

Em uma linha histórica, os próximos espaços relatam o processo de civilização da população piauiense: o Piauí Colônia, Império, República Velha e República Nova. O museu possui salas que caracterizam a população cívica, dominante, militar e política de cada uma dessas épocas. Para os períodos colonial e imperial, o museu exibe objetos diversos, a exemplo de imobiliários e louças em porcelanas de famílias tradicionais, bem como a pintura de Victor Meirelles de Lima, intitulada de Dom Pedro II e datada de 1875. Os fardamentos militares, armas de guerras e munições mostram a participação piauiense na luta pela independência do Brasil com a batalha do Jenipapo. 
Figura 3 - Aluna fazendo anotações sobre a obra "Dom Pedro II"

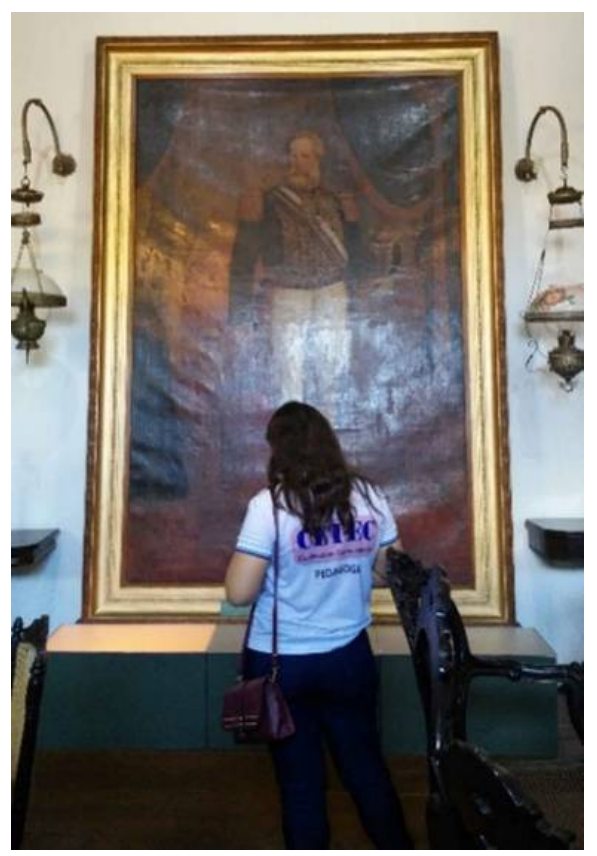

Fonte: Autores.

No intermédio desses recintos, encontra-se o baú de madeira rústico que guardava o dinheiro do governo piauiense transportado de Oeiras (primeira capital) para a nova capital, Teresina, em 1852. Enquanto o ambiente das Repúblicas traz consigo a visão das moradas piauienses nos estilos das fazendas do século XIX, arremete os participantes para a economia agropecuária da época, assim como dos costumes dos casarões que originaram muitas cidades do Estado, tal como Teresina. Isso é notório no ambiente de um quarto montado com mobiliário do período - uma cama de madeira grande e alta, urinol de madeira, pequenos santuários, máquina de costura, cômoda, espelho, cadeira, bilheira com potes e um rádio que ecoa repetidamente a voz do radialista Roque Moreira. Ainda sobre esses anos, a caracterização dos trâmites políticos se dá por meio dos quadros, pinturas e exposição de gabinetes de governadores do Piauí, como o de Eurípides Aguiar, eleito em 1916.

A iluminação e os sons da área que ovaciona a arte sacra piauiense conotam a ideia da religiosidade que fundamenta os princípios dessa prática artística, que "se refere à identidade cultural, considerando que as imagens produzidas fazem parte da cultura piauiense, seja nos altares domésticos, seja nos rituais religiosos nos templos ou ainda fora deles, ou quando são usadas para efeito de decoração" (LOPES, 2014, p. 28). A fé da população é expressa na devoção ou simplesmente na admiração aos diversos santos esculpidos presentes no local. Ali, também, se encontram as fachadas das mais conhecidas e importantes igrejas católicas das cidades do Estado, concebidas em pequenas réplicas de madeiras. 
Os piauienses produzem artesanatos que os identificam com muita criatividade, desenvoltura e através de matérias-primas disponibilizadas pela vasta diversidade de produtos cedidos pela natureza aos artesões. Nessa seção de artesanatos, pôde-se comtemplar os significados que eles têm para cada representação de classes sociais piauienses, através de amostras desses bens culturais nos mais diferentes tipos de materiais. $\mathrm{O}$ couro do boi, por exemplo, está diretamente vinculado aos vaqueiros e seus utensílios, como selas, gibões, chapéus, chicotes e muitos outros. Para cada material de produção como a pedra, metal, barro, madeira, traçados de palha, têxteis e bordados originados do algodão, o museu demonstra objetos, utensílios e ferramentas produzidos a partir deles e que se vinculam a tais classes.

Tambor de crioula, congada, cabeça de cuia e reisado são manifestações folclóricas típicas do Piauí, e no museu são apresentados simbolicamente ao público em forma de fantoches em pequenos teatros.

Figuras 4 e 5 - Representações do Bumba-meu-boi e Cabeça de Cuia
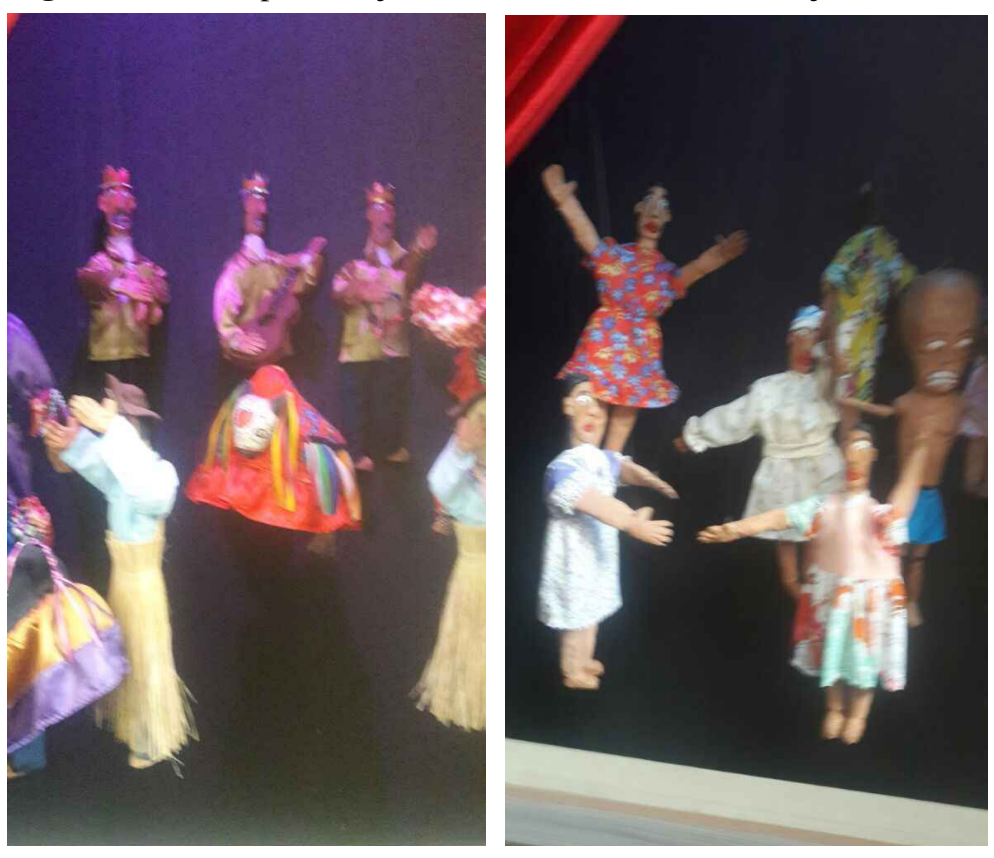

Fonte: Autores

Segundo a Carta Nacional de Folclore (COMISSÃO...,1995), o folclore se equipara à cultura popular como o resultado criativo das tradições representativas de identidades sociais em um conjunto de produções culturais de uma determinada comunidade. Então, as manifestações do folclore das comunidades pelos extremos do território piauiense demonstram uma identidade disseminada em camadas sociais. 
Dentre o folclore, o bumba-meu-boi é a cultura popular de maior representação dentro do espaço do museu, o grande boi colorido e seus personagens Nego Chico e Catirina são de um tamanho considerável e ficam dependurados e distribuídos no teto em um espaço reservado pra eles. Segundo Pedrazani (2010), apesar de ser uma festa nacional com diversas variações, em que a atenção nessa apresentação se volta para o boi que morre e ressuscita, isto em uma peça teatral no molde daqueles que participam dela, no Estado do Piauí ela recebe características particulares de destaque.

No campo das artes plásticas, a pinacoteca oferece um acervo rico em obras belas. "A Rendeira", retratada pela artista visual Fátima Campos, em uma escultura de cerâmica com tamanho de 3 metros, recepciona o público, esculpindo em suas mentes a imagem da mulher piauiense que, em muitas regiões, desenvolveu essa atividade considerada não somente econômica, mas também de expressividade cultural, sintetizando muitas histórias em uma única figura.

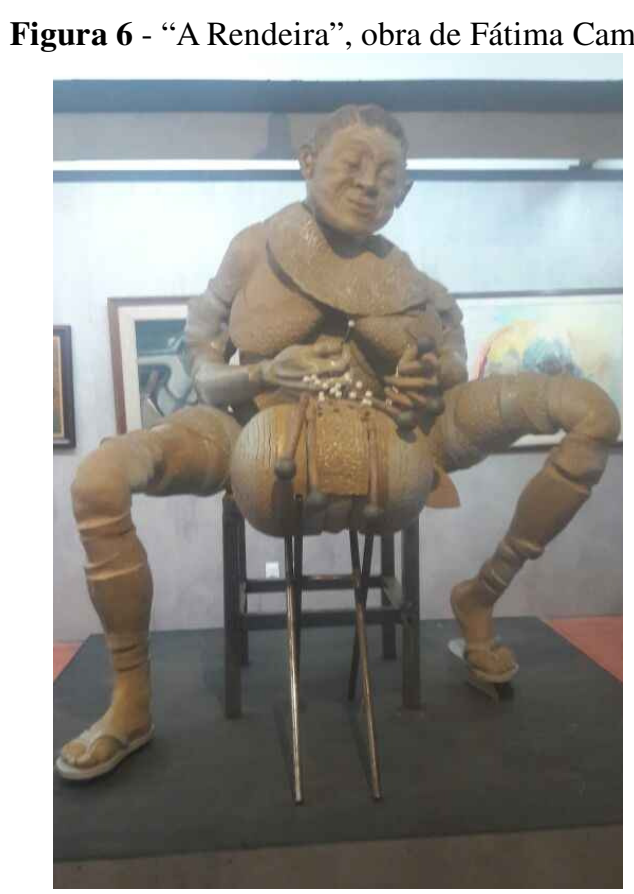

Fonte: Autores

A galeria de quadros e pinturas proporciona uma viagem no tempo e nos estilos artísticos e de sociedades de épocas diferentes, de datas passadas até artistas da contemporaneidade, tais como: Lucílio de Albuquerque, Afrânio Castelo Branco, Liz Medeiros, Píndaro Castelo Branco, Nonato Oliveira, Gabriel Archanjo, Cícero Manoel da Cunha, Hostyano Machado, Dalva Santana, Josefina Gonçalves, Fernando Costa, Dora Parentes, Fred Ramos, dentre outros. 
Com a intenção de proporcionar sempre amostras de artes e culturas diferentes do que se tem habitualmente e de forma permanente, o museu dispõe de 4 salas destinadas para exposições temporárias, porventura foi possível apreciar quadros que demonstravam a exuberância das belezas espalhadas Piauí abaixo, Piauí arriba. A exposição "Piauí Paisagens" trouxe fotografias de diversos cenários naturais do Estado, tais como: o encontro dos Rios Poti e Parnaíba, A Ponte Estaiada, o litoral do Piauí, a natureza nos carnaubais, poços jorrantes, as formações rochosas em paredões de pedras que adentram o Estado, a vida no campo dos piauienses e muito mais das cores, formas e belezas que o Piauí disponibiliza, todas imagens capturadas nas lentes dos fotógrafos Paulo Barros, Aureliano Muller, Manoel Soares e Juscelino Reis.

Diante do sentido, visto e ouvido, não sendo possível relatar tudo neste texto, a visita ao Museu do Piauí se encerra depois de um verdadeiro passeio por todas as suas salas. A partir de então, os alunos têm por atividade avaliativa um diálogo entre si, mediado pelo docente, com exposição oral dos relatos, capazes de demonstrar as percepções do conhecimento histórico, social, cultural e artístico adquiridos por meio do projeto. Os relatos foram subsídios para a composição da análise e discussão do estudo em foco.

\section{Os sentidos e significados: discursos de pertencimento}

O sentido, visto e ouvido na Casa de Odilon Nunes, consubstancia-se no vivido e experimentado. Diante disso, o processo educativo exige uma etapa reflexiva de transposição disso tudo aos sentidos e significados que atribuem à formação dos sujeitos e que esses atribuem à experiência. Nessas consubstanciações, Pimenta (2005) retrata que a identidade do professor se baseia nos saberes específicos da área, nos pedagógicos e nos de experiência, sendo este último o agregado das vivências de sua vida refletidas e submetidas a análises.

Diante desse processo reflexivo, evidencia-se a produção de sentido e significados, não como resultado final, mas como proposições passiveis de (re)reflexões e novos significados e sentidos. O fato é que toda a sinestesia propiciada pela visita ao Museu do Piauí não deveria ficar somente ali.

Portanto, a visitação a Casa de Odilon Nunes proporcionou um contato direto dos alunos com materiais relacionados à identidade do povo piauiense, o que despertou momentos de reflexões críticas acerca da formação de sua população, bem como da influência de cada etnia no processo de construção de identidade. Esses pensamentos fizeram com que os alunos correlacionassem hábitos cotidianos e recursos materiais advindos dos nossos antepassados indígenas e de descendência africana, alguns em um tempo e geografia não muito distantes dos nossos, como ao enfatizarem a escravidão implantada na Fazenda Serra Negra, localizada, praticamente, no "fundo do quintal" das casas dos discentes residentes em Aroazes, que admitiram muitas vezes não valorizarem essa riqueza histórica. 
Os fatores sociais resultantes dos processos históricos do Piauí decorridos em todos esses anos até a atualidade eram plenamente desconhecidos pela maioria dos alunos, corroborando a fala de Dias (1999 apud SOUZA, 2008, p. 9), em que piauienses desconhecem a história do Piauí. Pois, até então, os discentes, conforme suas falas, consideravam as condições econômicas, sociais e culturais apenas frutos da sorte ou do destino da população. Para muitos, foi surpreendente saber que Piauí foi um dos primeiros estados que, heroicamente, lutou pela independência nacional na Batalha do Jenipapo. No entanto, a aproximação com o contexto da história política nos mais diversos períodos e épocas ampliou a visão de entendimento sobre ações passadas que resultaram na sociedade dos dias atuais.

As expressões de fé percebidas no museu foram reconhecidas pelo alunado como algo semelhante ao que eles costumam praticar ou terem visto em seus ascendentes, como nos antecipou Lopes (2014) acerca da religiosidade no seio familiar, mas que tais expressões perdem forças na contemporaneidade. Assim como o folclore, que na visão dos discentes está sendo esquecido nos ambientes escolares, pois quando há alguma disseminação dessas manifestações não passa apenas do conhecimento teórico sem expressividade e aprofundamento na importância do teor cultural de tais representações.

Os alunos contemplaram um acervo de diversas obras da arte piauiense, em formas de fotografias, esculturas, artesanatos, pinturas e outras expressões. Tais obras foram vistas, por eles, como diretamente encravadas em algum pedacinho da dimensão territorial do Estado. E cada amostra artística ganhou uma significação simbólica capaz de, por si só, narrar um acontecimento, caracterizar uma comunidade, identificar os pertencimentos de classes, além de muitas outras funções. Como ao evidenciarem essa simbologia nos artesanatos de couro, tais como as indumentárias do vaqueiro, e reconhecer ali traços cotidianos da família e das realidades locais do lugar em que moram. Mais uma vez, Lopes $(2014$, p. 28), trata dos símbolos da região que "são identificados como meios de expressão de pertencimento a um lugar", sinalizando para a produção do patrimônio cultural imaterial.

Dos 14 alunos, nenhum conhecia o Museu do Piaú, pois nunca antes lhes foi oportunizado algo do gênero. De maneira pedagógica, humana e subjetiva, o que não descaracteriza essa experiência como um estudo cientifico, foi possível ver no olhar de cada pedagogo em formação o desejo por desvendar o que havia por trás de cada peça vista, assim como a curiosidade para entender as representações em cada objeto. Diante disso, é galardoador para o docente ver os sorrisos de satisfação e, mais ainda, o sentimento de gratidão dos acadêmicos por ter sido viabilizada uma aula diversificada, que foi além dos limítrofes da sala de aula, indo aos campos com base teórica e objetivos claros e bem definidos.

O acima mencionado traduz-se nas palavra de Larrosa (2016), acerca da experiência dos alunos e, mais ainda, do docente, vivência não somente sentida, mas que 
tocou, traspassou, moveu e comoveu, que gerou paixão, lógica e sentido pelo lugar de onde somos, como também pelo aguçar curioso das histórias não contadas. Isso torna-se pertinente para um estudo que se desenvolve ao traspassar um relato de experiência, como afirma o autor:

Se a experiência é o que nos acontece, e se o sujeito da experiência é um território de passagem, então a experiência é uma paixão. Não se pode captar a experiência a partir de uma reflexão do sujeito sobre si mesmo enquanto sujeito agente, a partir de uma teoria das condições de possibilidade da ação, mas a partir de uma lógica da paixão, uma reflexão do sujeito sobre si mesmo enquanto sujeito passional (LARROSA, 2016, p. 28).

Tudo isso coube em um encaixe perfeito ao objetivo do projeto de despertar nos acadêmicos, como futuros profissionais da educação, o senso de responsabilidade pela preservação e transmissão dos traços culturais para gerações atuais e futuras, o que foi considerado como alcançado.

Pelegrini e Funari (2008 apud NEGREIROS; PINHEIRO, 2012, p. 4) dizem que o "sentimento de pertencimento também fortalece as singularidades territoriais, permitindo que as populações residentes em dadas localidades primem pela transmissão de práticas por várias gerações". A partir disso, a compreensão histórica e cultural por parte dos pedagogos em formação parte do espaço próximo, do local, para então, posteriormente, ampliar-se para as esferas maiores. E isso é relatado por eles, que os seus lugares de falas ganharam novos sentidos, significados, traços e marcos identitários.

Porquanto, para os alunos, a experiência vivida fez com que se sentissem pertencentes ao povo piauiense, que gera outros piauienses, gerar no sentido de sensibilizar para a promoção e manutenção da identidade cultural do Estado, usando como prova de que isso é possível o exemplo do projeto aqui relatado, que foi capaz de provocar neles sentimentos, conhecimentos e pertencimentos à piauiensidade.

\section{Considerações finais}

Não se pretende com este relato entrar no mérito ou nas possíveis razões que contribuem para o desconhecimento da piauiensidade e/ou o não reconhecimento/valorização dela como uma identidade cultural. No entanto, com base nas inquietações docentes que deram origem ao projeto, na sua realização e avaliação, constatou-se que os acadêmicos de Pedagogia, e até mesmo o professor, conhecem superficialmente a arte, a cultura e a história piauienses e suas contribuições na formação de uma identidade cultural própria do Estado, o que transparece ser uma verdade que se reflete na maior parte da população piauiense. Compreende-se que essa forma de conhecer as raízes e memórias locais, em conjunto com as grandes mudanças que acontecem na contemporaneidade, causam um distanciamento ainda maior da identificação pessoal com as tradições piauienses. 
Outro aspecto mencionado dizia respeito aos impactos que esse nível de conhecimentos pode ocasionar no processo de ensino e aprendizagem de gerações futuras, ou mesmo atuais, no que tange à preservação da identidade cultural do estado piauiense. Fica evidente que, para preservar a identidade, é necessário, no mínimo, conhecê-la, mesmo que os profissionais da educação não vivam ou não se sintam parte cultural de uma comunidade ou lugar que se relaciona com seu campo de atuação.

No entanto, dos discursos emitidos e significados produzidos, extrai-se que quando o(a) pedagogo(a) vive e sente-se pertencente a uma identidade, à história que se relaciona diretamente com seu povo e local de trabalho, isso torna-se uma fonte de inspiração para interpretar o passado e compreender suas marcas de influências no presente, ampliando uma visão de preparação para o futuro. E, assim, em ações conscientes e reflexivas, torna-se responsável e agente de preservação e transmissão desses traços culturais para gerações atuais e futuras nos contextos escolares.

Em resposta ao último questionamento, o projeto foi capaz de demonstrar que ações semelhantes às que foram vivenciadas são marcos experienciais significativos para a construção dos saberes da experiência por qualquer ser humano, seja aluno de educação básica ou de educação superior. Dessa forma, o projeto não prendeu-se em responder sobre o que as instituições de educação estão fazendo, não obstante os discursos discentes contenham expressões que apontam para a urgência de haver mais ações com o intuito de manterem-se vivas as memórias da piauiensidade, mas pôs-se a demonstrar de forma prática uma atividade que contribui para esse fim e adaptável às mais diversas e possíveis necessidades educacionais.

Nos termos da piauiensidade como identidade cultural, o conjunto do projeto enquadra-se como uma referência para essa terminologia, vinculando-se aos aportes teóricos mencionados no decorrer do estudo, bem como às produções de sentidos e significados de alunos e professor que são piauienses e reconhecem-se dessa forma em termos identitários e de demarcação cultural, validando a piauiensidade.

Sendo assim, o estudo estabelece os projetos pedagógicos de ensino, pesquisa e/ou extensão de visita a espaços ricos e carregados de sentidos e significados culturais, históricos e artísticos como um instrumento importante e possível na trajetória formativa de alunos de cursos de nível superior, mais ainda, na formação de professores. Além do mais, pautada pedagogicamente em projetos, firma-os como procedimentos metodológicos interdisciplinares de fundamental relevância para a atuação docente, harmonizando-se às várias áreas de formação.

Conclui-se, então, que conhecer para se sentir pertencente é o primeiro passo, pois se torna inviável aos futuros professores preservarem aquilo que eles não reconhecem, não sabem a causa, importância ou mesmo influência desses aspectos artísticos, culturais e históricos em suas vidas na atualidade. 


\section{Referências}

BORGES, J. C. de F. Palavras que gestam o ser: relações possíveis entre a invenção da Piauiensidade e a escrita de Renato Castelo Branco. In: ENCONTRO NORDESTE DE HISTÓRIA DA MÍDIA, 2., 2012, Teresina. [Anais eletrônicos...]. Porto Alegre: UFRGS, 2012, p. 1-13. Disponível em: http://www.ufrgs.br/alcar/encontros-nacionais-1/encontrosregionais/nordeste/2o-encontro-2012/gt-2-2013-historia-da-publicidade-e-dacomunicacao-institucional/palavras-que-gestam-o-ser-relacoes-possiveis-entre-a-invencaoda-piauiensidade-e-a-escrita-de-renato-castelo-branco/view. Acesso em: 07 jun. 2020.

BRASIL. Lei no 9394/96, de 20 de dezembro de 1996. Estabelece as diretrizes e bases da Educação Nacional. Presidência da República. Brasília, 20 de dezembro de 1996. Disponível em: http://www.planalto.gov.br/Ccivil 03/leis/L9394.htm. Acesso em: 07 jun. 2020.

BRASIL. Secretaria de Educação Fundamental. Parâmetros Curriculares Nacionais: arte. Brasília: Ministério da Educação e Cultura/Secretaria de Educação Fundamental, 1997.

COMISSÃO NACIONAL DE FOLCLORE. Carta do folclore brasileiro. Salvador: CNF, 1995. Disponível em: http://www.fundaj.gov.br/geral/folclore/carta.pdf. Acesso em: 17 jun. 2020.

DA COSTA E SILVA, A. F. Hino do Piauí. 1823. Disponível em: https://pt.wikipedia.org/wiki/Hino_do_Piauí. Acesso em: 10 jul. 2020-.

DALTRO, M. R.; FARIA, A. A. Relato de experiência: uma narrativa científica na pósmodernidade. Estudos e Pesquisas em Psicologia, Rio de Janeiro, v. 19, n. 1, p. 223-237, 2019. Disponível em: https://www.epublicacoes.uerj.br/index.php/revispsi/article/view/43015. Acesso em: 10 maio 2020.

GOMES, J. Museu do Piauí é inaugurado e resgata cultura indígena. 45graus. Teresina, 2 mar. 2017. Disponível em https://www.45graus.com.br/geral/museu-do-piaui-einaugurado-e-resgata-cultura-indigena. Acesso em 13 jul. 2020.

HALL, S. A identidade cultural na pós-modernidade. Tradução: Tomaz Tadeu da Silva e Guaracira Lopes Louro. 9. ed. Rio de Janeiro: DP\&A, 2004.

LOPES, K. R. Arte Santeira do Piauí: entalhando imaginários. 2014. 99 f. Dissertação (Mestrado em Preservação Cultural) - Instituto do Patrimônio Histórico e Artístico Nacional, Rio de Janeiro, 2014. 
LARROSA, J. Tremores: escritos sobre experiência. 1. ed. 2. reimp. Tradução de Cristina Antunes, João Wanderley Geraldi. Belo Horizonte: Autêntica, 2016.

MINAYO, M. C. S. (org.). Pesquisa Social. Teoria, método e criatividade. 18. ed. Petrópolis: Vozes, 2001.

MORAES, D. L. O que é Piauiensidade. GP1. Teresina, 23 dez. 2012: Disponível em: http://www.gp1.com.br/colunistas/o-que-e-piauiensidade-280919.html. Acesso em: 09 jun. 2020.

NEGREIROS, V. R. de; PINHEIRO, Á. da P. História, memória e patrimônio cultural no Piauí. In: SIMPÓSIO NACIONAL DE HISTÓRIA CULTURAL, 2012, Teresina.

[Anais...] Teresina, UFPI, 2012, p. 1 -10. Disponível em:

http://gthistoriacultural.com.br/VIsimposio/anais/Valerio\%20Rosa\%20de\%20Negreiros\% 20\&\%20aurea\%20da\%20Paz\%20Pinheiro.pdf. Acesso em: 06 jun. 2020.

NÓVOA, A. A formação de professores e a profissão docente. In: NÓVOA, A. (org.). Os professores e a sua formação. Lisboa: Dom Quixote, 1992. p. 13-33.

OLISKOVICZ, K.; DAL PIVA, C. As estratégias didáticas no Ensino Superior: quando é o momento certo para se usar as estratégias didáticas no ensino superior? Revista da Educação, Anhanguera, v. 15, n. 19, p. 111-127. Disponível em: http://pgsskroton.com.br/seer/index.php/educ/article/view/1710/0. Acesso em: 09 jun. 2020.

OLIVEIRA, N. M. Folclore Brasileiro: Piauí. Rio de Janeiro: Funarte, 1977.

OLIVEIRA, N. M. O patrimônio pré-histórico do Piauí: perspectivas de preservação e estudo. Presença, Teresina, v. 2, n. 4, p. 45-46, dez. 1975.

PEDRAZANI, V. No "miolo" da festa: um estudo sobre o bumba-meu-boi do Piauí. 2010. 219 f. Tese (Doutorado em História Social) - Universidade Federal Fluminense, Niterói, 2010.

PIAUÍ. Fundação Cultural do Piauí. Bens Tombados no Piauí. Teresina:

FUNDAC/Coordenação de Registros e Conservação, 2009.

PIMENTA, S. G. Formação de professores: identidade e saberes da docência. In:

PIMENTA, S. G (org.). Saberes pedagógicos e atividade docente. 4. ed. São Paulo: Cortez, 2005. p. 15-33.

SOUZA, P. G. de C. História e Identidade: as narrativas da piauiensidade. 2008. $300 \mathrm{f}$.

Dissertação (Mestrado em História do Brasil) - Universidade Federal do Piauí, Teresina, 2008. 